\title{
USEFULNESS OF AN AD HOC QUESTIONNAIRE (ACRO-CQ) FOR THE SYSTEMATIC ASSESSMENT OF ACROMEGALY COMORBIDITIES AT DIAGNOSIS AND THEIR MANAGEMENT AT FOLLOW-UP
}

\section{This is the author's manuscript}

Original Citation:

\section{Availability:}

This version is available http://hdl.handle.net/2318/1564972

since 2017-09-19T09:57:01Z

Terms of use:

Open Access

Anyone can freely access the full text of works made available as "Open Access". Works made available under a Creative Commons license can be used according to the terms and conditions of said license. Use of all other works requires consent of the right holder (author or publisher) if not exempted from copyright protection by the applicable law. 
This is the author's final version of the contribution published as:

Guaraldi, F.; Gori, D.; Beccuti, G.; Prencipe, N.; Giordano, R.; Mints, Y.; Di

Giacomo, V. S.; Berton, A.; Gasco, V.; Ghigo, E.; Salvatori, R.; Grottoli, S.. USEFULNESS OF AN AD HOC QUESTIONNAIRE (ACRO-CQ) FOR THE SYSTEMATIC ASSESSMENT OF ACROMEGALY COMORBIDITIES AT DIAGNOSIS AND THEIR MANAGEMENT AT FOLLOW-UP. JOURNAL OF ENDOCRINOLOGICAL INVESTIGATION. None pp: 1-6.

When citing, please refer to the published version.

Link to this full text:

http://hdl.handle.net/2318/1564972 
USEFULNESS OF AN AD HOC QUESTIONNAIRE (ACRO- CQ) FOR THE SYSTEMATIC ASSESSMENT OF ACROMEGALY COMORBIDITIES AT DIAGNOSIS AND THEIR MANAGEMENT AT FOLLOW - UP

F. Guaraldi1 • D. Gori2 • G. Beccuti1 • N. Prencipe1 • R. Giordano1,3・Y. Mints4 • V. S. Di Giacomo1 • A. Berton1 • M. Lorente1 • V. Gasco1 • E. Ghigo1 • R. Salvatori4 • S. Grottoli1

* F. Guaraldi

federica.guaraldi@unito.it; federica.guaraldi@yahoo.it

1 Division of Endocrinology, Diabetes and Metabolism, Department of Medical Sciences, University of Turin, Corso Dogliotti, 14, 10126 Turin, Italy

2 Department of Biomedical and Neuromotor Sciences, DIBINEM, University of Bologna, 40126 Bologna, Italy

3 Department of Clinical and Biological Sciences, University of Turin, 10126 Turin, Italy

4 Division of Endocrinology, Diabetes and Metabolism, Department of Medicine, Pituitary Center, Johns Hopkins University School of Medicine, Baltimore, MD 21287, USA

Key words: Acromegaly • Comorbidities • Complications • Pituitary adenoma • Questionnaire validity 


\begin{abstract}
Purpose To determine the validity of a self-administered questionnaire (Acro-CQ) developed to systematically assess the presence, type and time of onset of acromegaly comorbidities.

Methods This is a cross-sectional study; 105 acromegaly patients and 147 controls with other types of pituitary adenoma, referred to a specialized Italian Center, autonomously compiled Acro-CQ in an outpatient clinical setting. To test its reliability in a different setting, Acro-CQ was administered via mail to 78 patients with acromegaly and 100 with other pituitary adenomas, referred to a specialized US Center. Data obtained from questionnaires in both set- tings were compared with medical records (gold standard). Results Demographics of patients and controls from both countries were similar. In both settings, $>95 \%$ of the questionnaires were completely filled; only one item was missed in the others. Concordance with medical record was excellent $(k>0.85)$ for most of the items, independently from the way of administration, patient age, gender and nationality, pituitary adenoma type and disease activity.

Conclusions Acro-CQ is an inexpensive, highly accepted from patients and reliable tool recommended to expedite systematic collection of relevant clinical data in acromeg- aly at diagnosis, to be replicated at follow-ups. This tool may guide a targeted, cost-effective management of com- plications. Moreover, it could be applied to retrieve data for survey studies in both acromegaly and other pituitary adenomas, as information is easily and rapidly accessible for statistical analysis.
\end{abstract}




\section{Introduction}

Acromegaly is a rare disorder resulting from chronic hypersecretion of growth hormone $(\mathrm{GH})$, mostly caused by a pituitary adenoma [1]. It mainly occurs sporadically, but may be seen in familial diseases [2]. It is characterized by dysmorphic facial and body features, anatomic and func- tional alterations of internal organs, metabolic, neoplastic and cardiovascular diseases (CVD), neurological symp- toms and hypopituitarism secondary to adenoma mass effect, overall responsible for high morbidity and mortality $[1,3,4]$. Because of the disease complexity and the vari- able physician approach to patients, it is difficult to obtain a systematic assessment of the numerous complications induced by GH hypersecretion-whose risk and severity are related to disease duration and not always reversed by biochemical control — and its treatments $[3,5]$ and to rep- licate it at the various follow-ups. Moreover, because of economic restrictions imposed to the healthcare systems, a more personalized, cost-effective screening of complica- tions would be very important in these patients.

Based on these premises, our study aimed at assessing the validity of a questionnaire purposely developed to sys- tematically assess, at diagnosis and during follow-up, the type, prevalence and time of onset of relevant disorders typically associated with acromegaly and its treatments, to be used in the clinical practice for a patient-targeted cost- effective management.

\section{Materials and methods}

Two hundred and fifty-two patients, 105 with acromegaly due to a GH-secreting adenoma (cases; 66 F; mean age $59.0 \pm 14.8$ years) and 147 with other types of pituitary adenoma (controls; 87 prolactinomas and 60 non-function- ing adenomas, NFA; $80 \mathrm{~F}$; mean age $55.0 \pm 16.1$ years) consecutively referred to the Division of Endocrinology, Diabetes and Metabolism, University of Turin (Italy) from November 2012 to May 2014, were evaluated. 
The diagnosis of acromegaly was based on the pres- ence of suggestive clinical features associated with MRI evidence of a pituitary adenoma, elevated age-adjusted IGF-I levels and nadir GH after oral glucose load $>1 \mu \mathrm{g} / 1$ [5]. Disease was considered controlled in the presence of normal age- and genderadjusted serum IGF-I levels and random GH $<1 \mu \mathrm{g} / 1$ during treatment and cured when these criteria were fulfilled after treatment discontinua- tion [5]. Prolactinoma was diagnosed in the presence of elevated serum prolactin levels and MRI evidence of pituitary adenoma, after excluding other causes of hyper- prolactinemia and mixed GH-/PRL-secreting tumors. Prolactin levels at diagnosis, together with clinical, bio- chemical and radiological findings and (in some cases) response to therapy with dopamine agonists, contrib- uted to differential diagnosis between prolactinomas and NFA [6]. Remission was defined as serum prolactin level in the normal range during medical treatment; patients were considered cured when prolactin levels were in the normal range after treatment discontinuation. NFA was defined as MRI-detected pituitary adenoma in the absence of hormone hypersecretion [7]. Patients with hypopituitarism were adequately substituted with hormo- nal replacement therapy.

Patients were asked to fill, in an outpatient setting, a self-administered, 22-item questionnaire (Acro$\mathrm{CQ}$ ), pur- posely developed to systematically assess the presence of (1) omorbidities typically associated with acromegaly and its treatment, including metabolic (glucose, lipid and bone metabolism), CVD and neoplastic disorders; intestinal diverticulosis/diverticulitis; gallbladder and kidney stones; and goiter and carpal tunnel syndrome and (2) family his- tory of pituitary adenoma. For each comorbidity, patients were also asked to indicate their age at diagnosis, and for neoplasia, the type and location (Fig. 1).

The choice of comorbidities to be investigated by the questionnaire was made by a team of neuroendocrinolo- gists based on their clinical practice and expert reviews/ international guidelines: Disorders typically associated with acromegaly and deserving treatment to prevent long- term morbidity and mortality were included $[3,5,8]$. To improve patient understanding and compliance, we formu- lated simple and direct questions, using the easiest possible terms. 
To determine Acro-CQ validity, the same data collected through questionnaire's administration were retrieved from medical records — considered the gold standard-together with information on adenoma size at diagnosis, hormonal parameters at diagnosis and follow-up (to determine dis- ease activity and the adequacy of replacement therapy in case of hypopituitarism), the presence of residual adenoma and type and duration of the various treatments.

With regard to associated disorders ("comorbidities"), acromegaly patients had been screened at diagnosis and follow-up according to international guidelines [9], while controls had been evaluated only in the presence of sug- gestive symptoms and/or risk factors. Based on the estab- lished promoting role of chronic GH hypersecretion on the development of systemic disorders and the mean reported delay in acromegaly diagnosis $(2.5-10$ years on average) [8], comorbidities diagnosed $\leq 5$ years before acromegaly were arbitrarily defined "complications", and those affect- ing $\geq 10$ patients were considered "common".

Hypertension was defined as a systolic blood pressure $\geq 140 \mathrm{mmHg}$ and/or a diastolic blood pressure $\geq 90 \mathrm{mmHg}$ or the use of antihypertensive drugs. International criteria were applied for the diagnosis of impaired fasting glucose, impaired glucose tolerance and diabetes [10], dyslipidemia [11], osteopenia and osteoporosis [12]. The diagnosis of thyroid hyperplasia/goiter was established by ultrasound examination.

To confirm the concordance between self-reported dis- ease and medical record in a different geographical setting, the study was extended to 178 patients, 78 with acromegaly and 100 with other pituitary adenomas, referred to the Pitu- itary Center of the Johns Hopkins University Hospital, Baltimore (USA). At this purpose, Acro-CQ, originally formu- lated in Italian, was translated in English and reviewed by a native speaker. Patients were contacted by mail, filled the questionnaire at home and returned it by mail using prepaid stamped envelops.

The questionnaire was returned by 35 acromegaly patients (20 F; mean age $56.1 \pm 11.6$ years) and 40 patients with other types of pituitary adenoma (controls; $21 \mathrm{~F}$; mean age $59.3 \pm 11.0$ years; 14 
prolactinomas and 26 NFA). Patients' main demographics and clinical characteristics are summarized in Table 1.

The study was approved by the Hospital Ethics Commit- tees of both Turin University and Johns Hopkins Univer- sity. Only patients able to autonomously read and fill the questionnaire and give their written informed consent to participate in the study were included.

\section{Statistical analysis}

Prevalence of comorbidities was defined for cases and con- trols; in patients with acromegaly, we also calculated the prevalence, temporal distribution and median time interval between diagnosis and complication's onset. Inter-group differences were assessed using Chi-square test or Fisher's exact test $(\mathrm{n} \leq 5)$; a $\mathrm{p}$ value $<0.05$ was considered statisti- cally significant. Multivariate logistic regression analysis, adjusted for gender and age at time of response to the ques- tionnaire, was performed to test differences in prevalence of comorbidities between groups; odds ratios were also cal- culated. The concordance between clinical record and ques- tionnaire was evaluated by Cohen's Kappa coefficient [13]: For $\mathrm{k} \leq 0.6$, logistic regression was performed to assess the influence of gender and age at evaluation (independent predictors of the model) on questionnaire response. Gender differences in answering to the questionnaire were calcu- lated by Fisher's exact test.

Statistical analysis was performed with STATA Statis- tical Software, release 12 (StataCorp LP, College Station, TX, USA).

\section{Results}


The groups of patients with acromegaly and controls from Italy and USA were homogeneous for gender and age dis- tribution, at diagnosis of pituitary adenoma and at evalua- tion (Table 1).

Neoplasia was more frequently associated with acro- megaly than other pituitary adenomas, although the statistical significance was reached only for gastroin- testinal $(\mathrm{p}<0.004 ; \mathrm{p}<0.0001$ for colonic polyposis) and genitourinary neoplasia $(\mathrm{p}<0.01)$ (Supplementary Table 1$)$. The great majority of the tumors, except for hematologic ones, were benign, as detailed in Table 2.

Acromegaly patients were at higher risk of metabolic abnormalities (impaired glucose tolerance; IGT/diabetes; dyslipidemia; osteopenia/osteoporosis), hypertension, hyper- trophic/dilatative and valvular cardiac disorders $(\mathrm{p}<0.0005)$, but not for arrhythmias, ischemic events or aneurysms. Gallbladder $(\mathrm{p}<0.0001)$ and kidney stones $(\mathrm{p}<0.004)$, intesti- nal diverticulosis $(\mathrm{p}<0.0001)$, goiter $(\mathrm{p}<$ 0.0001), obstructive sleep apnea $(\mathrm{p}=0.004)$ and carpal tunnel syndrome $(\mathrm{p}<0.0001)$ were also more frequent in acromegaly. The majority of complications appeared soon after acromegaly diagnosis (median $\leq 5.5$ years) (Supplementary Table 1$)$. In

both groups, patients typically developed gallbladder and kidney stones during SSA treatment (Supplementary Table 1).

Familial history of pituitary adenoma was present in four patients with acromegaly and one with NFA (4/5 were males).

In the Italian cohort, questionnaires were completely filled by $98.9 \%$ of acromegaly patients, and by $95.7 \%$ of the controls; only one item (typically diverticulosis, IGT/ diabetes and genitourinary benign neoplasia) was missing in incomplete questionnaires (Supplementary Table 2).

Concordance between questionnaire and medical record was good or excellent $(k>0.6)$ for all items in both groups, except for genitourinary neoplasia $(\mathrm{k}=0.54)$, CVD $(\mathrm{k}=0.45)$ and dyslipidemia $(\mathrm{k}=$ 0.51), underreported in acromegaly. Logistic regression analysis showed a higher number of mismatches in males for genitourinary benign neoplasia, but no gender differences for CVD and 
dyslipi- demia. Concordance between questionnaire and medical record was negatively associated with age at the time of questionnaire's compilation for genitourinary benign neoplasia, CVD and IGT.

The administration of Acro-CQ to the Baltimore cohort confirmed the excellent rate of e-questionnaire completion (97\% in acromegaly and $97.7 \%$ in controls of the returned questionnaires were completely filled), as well the high concordance between questionnaire and medical record, being $\mathrm{k}>0.7$ for all items except for thyroid hyperplasia $(\mathrm{k}=0.4)$, underreported in the control group.

\section{Discussion}

We present the results of a cross-sectional study assessing the validity of Acro-CQ, the first questionnaire developed to systematically assess at diagnosis, and monitor during follow-up, the presence of comorbidities typically associ- ated with acromegaly, thus improving patient management. Acromegaly is a chronic disease associated with a large number of comorbidities, typically presenting in the first years after diagnosis and not always reversed after disease control, responsible for a significant increase in morbidity, impairment of the quality of life and high mortality rate [1,3-5]. At the same time, due to the disease complexity and variable physi- cian approach to patients, it is currently difficult to obtain a systematic evaluation at diagnosis to be replicated at follow- ups. Moreover, because of economic restrictions imposed on the healthcare systems, a more personalized monitoring of complications would be extremely important for a cost-effec- tive patient management. For this purpose, historical informa- tion retrieved from patients through validated tools could be extremely useful, especially for those with limited available medical data evaluated in specialized medical centers geographically far from their residence and referring physicians.

According to our data, Acro-CQ is a valid tool for an easy, comprehensive and inexpensive assessment and mon- itoring of acromegaly comorbidities. Indeed, the patient acceptance rate and concordance with medical record are very high, independently from patient age, gender, lan- guage and clinical setting. The success of the questionnaire is likely based on the clear format, close-ended questions with 
dichotomous answers formulated using an easy and straightforward language [14, 15]. When questionnaire was mailed, the percentage of return was overall satisfactory (42\%). Providing patients with prepaid stamped envelops may have increased the rate of response [16].

On the other hand, a minor limitation to the clinical application of the questionnaire at each follow-up visits could be the relatively long time needed to completely fill the questionnaire in patients with many comorbidities.

Moreover, being the questionnaire self-administered, we demonstrated for the first time that patients with acromegaly and, more generally, pituitary adenomas are highly aware about disorders associated with their condition.

Finally, using both questionnaires and medical records, the prevalence data of a great variety of disorders were retrieved from a large and homogeneous cohort of patients with acromegaly, for the first time compared to patients with other types of pituitary adenoma. Data analysis dem- onstrated a significantly higher prevalence of metabolic and cardiovascular disorders, as well as thyroid hyperplasia, carpal tunnel syndrome and intestinal diverticulosis in acromegaly than in other pituitary adenomas, confirming percentages obtained from previous studies considering acromegaly patients per se, or in comparison with healthy subjects [3,17-22]. On the contrary, the prevalence of obstructive sleep apnea was lower in our cohort than previ- ously reported (19 vs. 60-90\%) [3], underling the impor- tance of formal assessment of sleep disorders, as symptoms leading to polysomnography investigation are frequently underestimated.

Independently of the type of pituitary adenoma, a strong association was found between SSA therapy and the devel- opment of gallstones (confirming the literature data [23]) and kidney stones. Several mechanisms for which SSA contribute to gallstones formation have been postulated, leading to increased bile concentration and lithogenic changes in its composition, together with physical conditions favoring micro-crystal precipitation and stone for- mation. Conversely, mechanisms that could 
cause SSA to predispose to kidney stones formation remain unknown, as chronic administration of SSA apparently does not impact on calcium metabolism [24].

Whether the risk of cancer and related mortality is increased by GH hypersecretion is debated [3, 20, $21,25]$. We found that the prevalence of neoplasia in acro- megaly was not significantly higher than in other pituitary adenomas, except for gastrointestinal and genitourinary tumors (Supplementary Table 1), being the great majority of these lesions benign (Table 2). Rates of thyroid hyper- plasia, gastrointestinal and genitourinary benign tumors were in line with the literature $[3,21,26]$, but we did not observe the increased risk of malignant transformation of thyroid nodules and intestinal polyps reported by larger cohort studies and meta-analysis $[3,20,21,25]$, possibly due to the smaller sample size.

In conclusion, we recommend Acro-CQ for an easy, inexpensive, reproducible and comprehensive assessment of relevant comorbidities associated with acromegaly (but also with other pituitary adenomas), at diagnosis and follow-up visits, to guide a patient-targeted and cost-effective management. Because it takes a relatively long time to completely fill the questionnaire in patients with many comorbidities, physicians could decide in more complex patients, espe- cially those requiring very frequent visits, to administer the Acro-CQ only during selected follow-up visits.

The Acro-CQ can also be used to retrieve data for sur- vey studies in the field of pituitary disorders, as clinical information is easily and rapidly accessible for statistical analysis.

The application of this tool to larger cohorts of patients (i.e., multicenter studies) would be extremely useful to bet- ter determine the validity of the suggested tool, both in the clinical and research settings.

Compliance with ethical standards

Conflict of interest RS serves in an advisory board for Novartis and receives research support from Novartis, Ipsen and Pfizer. EG serves in an advisory board for Pfizer. SG serves in an advisory board 
for Pfizer and received support from Novartis, Ipsen, Italfarmaco and Pfizer. The other authors declare they have no conflict of interest.

Ethical approval All procedures performed in studies involving human participants were in accordance with the ethical standards of the institutional research committee and the Helsinki Declaration. This article does not contain any studies with animals performed by any of the authors.

Informed consent All patients included in the study gave their informed consent.

Funding This research did not receive any specific grant from any funding agency in the public, commercial or not-for-profit sector.

\section{References}

1. Chanson P, Salenave S, Kamenicky P, Cazabat L, Young J (2009) Pituitary tumours: acromegaly. Best Pract Res Clin Endocrinol Metab 23:555-574

2. Daly AF, Beckers A (2015) Familial isolated pituitary adenomas (FIPA) and mutations in the aryl hydrocarbon receptor inter- acting protein (AIP) gene. Endocrinol Metab Clin North Am 44:19-25

3. Colao A, Ferone D, Marzullo P, Lombardi G (2004) Systemic complications of acromegaly: epidemiology, pathogenesis, and management. Endocr Rev 25:102-152

4. Jurcut R, Ga loiu S, Florian A, Vla daia A, Ioniţa OR, Amzulescu MS, Baciu I, Popescu BA, Cocolescu M, Ginghina C (2014) Quantifying subtle changes in cardiovascular mechanics in acromegaly: a Doppler myocardial imaging study. J Endocrinol Invest 37:1081-1090 
5. Giustina A, Chanson P, Bronstein MD et al (2010) Acromegaly Consensus Group: a consensus on criteria for cure of acromeg- aly. J Clin Endocrinol Metab 95:3141-3148

6. Melmed S, Casanueva FF, Hoffman AR et al (2011) Diagnosis and treatment of hyperprolactinemia: an Endocrine Society clini- cal practice guideline. J Clin Endocrinol Metab 96:273-288

7. Molitch ME (2014) Nonfunctioning pituitary tumors. Handb Clin Neurol 124:167-184

8. Giustina A, Chanson P, Kleinberg D et al (2014) Acromegaly Consensus Group: expert consensus document: a consensus on the medical treatment of acromegaly. Nat Rev Endocrinol $10: 243-248$

9. Melmed S, Casanueva FF, Klibanski A et al (2013) A consen- sus on the diagnosis and treatment of acromegaly complications. Pituitary 16:294-302

10. Rydén L, Grant PJ, Anker SD et al (2013) ESC Guidelines on diabetes, pre-diabetes, and cardiovascular diseases developed in collaboration with the EASD: the Task Force on diabetes, prediabetes, and cardiovascular diseases of the European Society of Cardiology (ESC) and developed in collaboration with the Euro- pean Association for the Study of Diabetes (EASD). Eur Heart J 34:30353087

11. Smith SC Jr, Grundy SM (2014) 2013 ACC/AHA guideline rec- ommends fixed-dose strategies instead of targeted goals to lower blood cholesterol. J Am Coll Cardiol 64:601-612

12. Florence R, Allen S, Benedict L et al (2013) Diagnosis and treat- ment of osteoporosis. http://www.icsi.org/_asset/vnw0c3/Osteo. pdf. Accessed 12 July 2015

13. Cohen J (1960) A coefficient of agreement for nominal scales. Educ Psychol Meas 20:37-46 14. Colosi L (2006) http://www.human.cornell.edu/pam/outreach/ parenting/parents/upload/Designing-20an-20Effective-20Ques- tionnaire.pdf. Accessed 12 July 2015 15. Burns KEA, Duffett M, Kho ME et al (2012) A guide for the design and conduct of seladministered surveys of clinicians. Can Med Ass J 179:245-252 
16. Lavelle K, Todd C, Campbell M (2008) Do postage stamps versus pre-paid envelopes increase responses to patient mail surveys? A randomized controlled trial. BMC Health Serv Res 8:113

17. Alexopoulou O, Bex M, Kamenicky P, Bessomo Mvoula A, Chanson P, Maiter D (2014) Prevalence and risk factors of impaired glucose tolerance and diabetes mellitus at diagnosis of acromegaly: a study in 148 patients. Pituitary 17:81-89

18. Mosca S, Paolillo S, Colao A et al (2013) Cardiovascular involvement in patients affected by acromegaly: an appraisal. Int J Cardiol 167:1712-1718

19. Mazziotti G, Biagioli E, Maffezzoni F, Spinello M, Serra V, Mar- oldi R, Floriani I, Giustina A et al (2015) Bone turnover, bone mineral density and fracture risk in acromegaly: a metanalysis. J Clin Endocrinol Metab 100:384-394

20. Reverter JL, Fajardo C, Resmini E et al (2014) Benign and malignant nodular thyroid disease in acromegaly. Is a routine thyroid ultrasound evaluation advisable? PLoS One 9:e104174

21. Jenkins PJ (2006) Cancers associated with acromegaly. Neuroen- docrinology 83:218-223

22. Wassenaar MJ, Cazemier M, Biermasz NR et al (2010) Acro- megaly is associated with an increased prevalence of colonic diverticula: a case-control study. J Clin Endocrinol Metab 95:20732079

23. Attanasio R, Mainolfi A, Grimaldi F et al (2008) Somatostatin analogs and gallstones: a retrospective survey on a large series of acromegalic patients. J Endocrinol Invest 31:704-710

24. Ajmal A, Haghshenas A, Attarian S et al (2014) The effect of somatostatin analogs on vitamin D and calcium concentrations in patients withacromegaly. Pituitary 17:366-373. doi:10.1007/ s11102013-0514-0

25. Wolinski K, Czarnywojtek A, Ruchala M (2014) Risk of thyroid nodular disease and thyroid cancer in patients with acromeg- aly—meta-analysis and systematic review. PLoS One 9:e88787

26. Rokkas T, Pistiolas D, Sechopoulos P, Margantinis G, Koukoulis G (2008) Risk of colorectal neoplasm in patients with acromeg- aly: a meta-analysis. World J Gastroenterol 14:3484-3489 
Pituitary adenoma type

Year of diagnosis

1. Have you ever been diagnosed with a benign/malignant tumour of the central nervous system (excluding pituitary adenoma)?

o Yes o No

la. If yes, which kind? Which location?

1b. What was your age at diagnosis

2. Have you ever been diagnosed with a benign/malignant tumour in your face/head (eyes, mouth, nose, ears; skin, bones and muscles) or neck (thyroid, parathyroid glands; skin, muscles)? o Yes o No

2a. If yes, which kind? Which location?

2b. What was your age at diagnosis

3. Have you ever been diagnosed with a benign/malignant breast tumour?

o Yes o No

3a. If yes, which kind? Which location?

3b. What was your age at diagnosis

4. Have you ever been diagnosed with a benign/malignant tumour of the respiratory apparatus (trachea/windpipe, airways, lungs)?

o Yes o No

4a. If yes, which kind? Which location?

4b. What was your age at diagnosis

5. Have you ever been diagnosed with a benign/malignant tumour of the digestive system (esophagus, stomach, intestine, colon, rectum, liver, pancreas, gallbladder, bile ducts)? o Yes o No

5a. If yes, which kind? Which location?

5b. What was your age at diagnosis

6. Have you ever been diagnosed with a benign/malignant tumour of the urogenital tract (bladder; prostate, testicles for males; uterus, ovaries for females)? 6a. If yes, which kind? Which location?

$6 \mathrm{~b}$. What was your age at diagnosis

7. Have you ever been diagnosed with a benign/malignant tumour of the adrenal gland? o Yes o No 7a. If yes, which kind? Which location?

7b. What was your age at diagnosis

8. Have you ever been diagnosed with a benign/malignant tumour of muscles or bones? o Yes o No 8a. If yes, which kind? Which location?

8 b. What was your age at diagnosis .

9. Have you ever been diagnosed with a benign/malignant tumour of the skin?

- Yes o No

9a. If yes, which kind? Which location?

9b. What was your age at diagnosis 
10. Have you ever been diagnosed with a haematological malignancy (lymphoma, leukaemia, myeloma)?

10a. If yes, which kind? Which location?

$10 \mathrm{~b}$. What was your age at diagnosis

11. Do you suffer from gallbladder/bile ducts stones?

o Yes oNo

If yes, what was your age at diagnosis?

12. Do you suffer from kidney stones?

o Yes o No

If yes, what was your age at diagnosis?

13. Do you suffer from reduced bone density (osteopenia/osteoporosis)?

o Yes o No

If yes, what was your age at diagnosis?

14. Do you suffer from intestinal diverticulosis/diverticulitis?

o Yes o No

If yes, what was your age at diagnosis?

15. Do you suffer from high blood pressure (hypertension)?

o Yes o No

If yes, what was your age at diagnosis?

16. Do you suffer from other cardiovascular diseases (ischaemic, valvular, rhythmic disorders; cardiomegaly/cardiac hypertrophy; vascular aneurysms; etc.)?

o Yes o No

$16 \mathrm{a}$. If yes, which kind?

$16 \mathrm{~b}$. What was your age at diagnosis?

17. Do you suffer from impaired glucose intolerance/diabetes mellitus?

o Yes oNo

$17 \mathrm{a}$. What was your age at diagnosis?

18. Do you suffer from increased cholesterol and/or triglycerides levels (hypercholesterolemia/hypertriglyceridemia)?

o Yes o No

If yes, what was your age at diagnosis?

19. Do you suffer from thyroid disorders excluded benign/malignant tumours (i.e. goitre, thyroiditis)?

$$
\text { o Yes o No }
$$

If yes, what was your age at diagnosis?

20. Have you ever been diagnosed with carpal tunnel syndrome?

o Yes o No

If yes, what was your age at diagnosis?

21. Do you suffer from sleep apnoea syndrome (OSAS)?

o Yes oNo

If yes, what was your age at diagnosis?

22. Has any of your family member been diagnosed with pituitary adenoma?

o Yes o No

22a. If yes, what's your degree of kinship with this person?

22b. What type of adenoma does this person suffer from? 
Table 1 Patients demographics and main clinical features

\begin{tabular}{|c|c|c|c|c|c|c|c|c|c|c|c|}
\hline \multirow[t]{3}{*}{ Group } & \multirow[t]{3}{*}{$N$} & \multirow[t]{3}{*}{$\mathrm{F}(\%)$} & \multirow{3}{*}{$\begin{array}{l}\text { Age at diag- } \\
\text { nosis (yr; } \\
\text { mean } \pm \mathrm{SD} \text { ) }\end{array}$} & \multirow{3}{*}{$\begin{array}{l}\text { Age at eval- } \\
\text { uation (yr; } \\
\text { mean } \pm S D)\end{array}$} & \multicolumn{5}{|l|}{ Treatment } & \multirow{3}{*}{$\begin{array}{l}\text { Residual } \\
\text { tumor }(\%)\end{array}$} & \multirow{3}{*}{$\begin{array}{l}\text { Hypopituita- } \\
\text { rism }(\%)\end{array}$} \\
\hline & & & & & Surgery $(\%)$ & $\mathrm{RT}(\mathscr{F})$ & Medical th & herapy & & & \\
\hline & & & & & & & $\operatorname{SSA}(\%)$ & $\begin{array}{l}\text { D2 agonists } \\
(\%)\end{array}$ & $\begin{array}{l}\text { Pegviso- } \\
\text { mant }(\%)\end{array}$ & & \\
\hline \multicolumn{12}{|c|}{ Acromegaly (cases) } \\
\hline Turin & 105 & 62.8 & $47.0 \pm 13.7$ & $59.0 \pm 14.8$ & 56.2 & 21.9 & 94.3 & 53.3 & 27.6 & 70.5 & 36.2 \\
\hline Baltimore & 35 & 51.2 & $47.0 \pm 12.0$ & $56.1 \pm 11.6$ & 91.4 & 28.6 & 62.8 & 31.4 & 31.4 & 48.6 & 34.3 \\
\hline \multicolumn{12}{|c|}{ Other pituitary adenomas (controls) } \\
\hline Turin & 147 & 54.4 & $45.0 \pm 16.8$ & $55.0 \pm 16.1$ & 34 & 4.7 & 5.4 & 63.9 & 0 & 70 & 38.1 \\
\hline Baltimore & 40 & 52.5 & $49.9 \pm 11.7$ & $59.3 \pm 11.0$ & 60 & 0 & 0 & 32.5 & 0 & 70 & 42.5 \\
\hline
\end{tabular}

$D 2$ agonists dopamine agonists, $F$ females, $N$ number, pts patients, $R T$ radiation therapy, SD standard deviation, SSA somatostatin analogues, $y r$ years 
Table 2 Type and distribution of neoplasia in patients with acromegaly (cases) and other types of pituitary adenoma (controls) in the Turin cohort

\begin{tabular}{|c|c|c|}
\hline Type of neoplasia & Acromegaly $(N=105)$ & Controls $(N=147)$ \\
\hline \multicolumn{3}{|l|}{ I. Central nervous system } \\
\hline Meningioma & 6 & 2 \\
\hline Neurinoma & - & 1 \\
\hline Craniopharyngioma & - & 1 \\
\hline Neurofibroma & - & 1 \\
\hline \multicolumn{3}{|l|}{ II. Head and neck } \\
\hline Ethmoidal polyps & 1 & - \\
\hline Epithelioma & 1 & 1 \\
\hline $\begin{array}{l}\text { Cavernous heman- } \\
\text { gioma }\end{array}$ & 1 & - \\
\hline Papilloma & - & 1 \\
\hline Oncocytoma & - & 1 \\
\hline $\begin{array}{l}\text { Thyroid papillary } \\
\text { carcinoma }\end{array}$ & 1 & - \\
\hline Parathyroid adenomas & 3 & - \\
\hline \multicolumn{3}{|l|}{ III. Breast cancer } \\
\hline Fibroadenoma & 9 & 3 \\
\hline Lypoma & 1 & 1 \\
\hline Carcinoma & 1 & 3 \\
\hline \multicolumn{3}{|l|}{ IV. Respiratory apparatus } \\
\hline Carcinoid & 1 & - \\
\hline $\begin{array}{l}\text { Differentiated neuroen- } \\
\text { docrine tumor }\end{array}$ & 1 & - \\
\hline Neuroblastoma & - & 1 \\
\hline \multicolumn{3}{|c|}{ V. Gastrointestinal apparatus (excluding gastrointestinal polyps) } \\
\hline Hepatic hemangioma & 9 & 1 \\
\hline $\begin{array}{l}\text { Hepatic adenocarci- } \\
\text { noma }\end{array}$ & 1 & - \\
\hline $\begin{array}{l}\text { Gallbladder adeno- } \\
\text { myoma }\end{array}$ & 5 & 1 \\
\hline Intestinal lipoma & 1 & - \\
\hline Colon carcinoma & 1 & 1 \\
\hline Gastric adenoma & - & 1 \\
\hline Gastric carcinoma & - & 1 \\
\hline Mesenteric carcinoma & & 1 \\
\hline \multicolumn{3}{|c|}{ VI. Genitourinary apparatus } \\
\hline Uterine leiomyoma & 16 & 13 \\
\hline Uterine carcinoma & - & 3 \\
\hline Ovarian cystadenoma & 1 & - \\
\hline Prostate adenoma & 16 & 14 \\
\hline Prostate carcinoma & - & 1 \\
\hline Testicular teratoma & - & 1 \\
\hline Renal adenoma & - & 1 \\
\hline Renal angiomyolipoma & 4 & - \\
\hline Renal oncocytoma & 1 & - \\
\hline Renal carcinoma & 3 & 2 \\
\hline Bladder carcinoma & 1 & 3 \\
\hline
\end{tabular}


Table 2 continued

\begin{tabular}{|c|c|c|}
\hline Type of neoplasia & Acromegaly $(N=105)$ & Controls $(N=147)$ \\
\hline \multicolumn{3}{|l|}{ VII. Adrenal gland } \\
\hline Incidentaloma & 2 & 3 \\
\hline Hemangioma & - & 1 \\
\hline \multicolumn{3}{|c|}{ VIII. Muscle-skeleton apparatus } \\
\hline Lypoma & 1 & 1 \\
\hline Neuroma & - & 1 \\
\hline \multicolumn{3}{|l|}{$I X$. Skin } \\
\hline Hemangioma & 1 & - \\
\hline Melanoma & 2 & - \\
\hline $\begin{array}{l}\text { Atypical melanocytic } \\
\text { hyperplasia }\end{array}$ & - & 1 \\
\hline Epithelioma & - & 1 \\
\hline \multicolumn{3}{|c|}{ X. Hematologic malignancies } \\
\hline Multiple myeloma & - & 1 \\
\hline $\begin{array}{l}\text { Non-Hodgkin lym- } \\
\text { phoma }\end{array}$ & - & 1 \\
\hline $\begin{array}{l}\text { Acute lymphoblastic } \\
\text { leukemia }\end{array}$ & - & - \\
\hline
\end{tabular}

